\title{
DEVIATION FROM THE CARRYING CAPACITY FOR PHYSICIANS AND GROWTH RATE OF PHYSICIAN SUPPLY: THE TAIWAN CASE
}

\author{
TUNG-LIANG ChIANG \\ Center for Health Policy Research, College of Public Health, National Taiwan University, Taipei, \\ Taiwan, Republic of China
}

\begin{abstract}
This study applies the theory of carrying capacity to examine the effects of market forces on the location pattern of physicians in Taiwan between 1974 and 1982. The data for the analysis were collected from governmental publications. The township was selected as the geographic unit of analysis. By using a regression model of physician supply, this study developed a proxy for physician carrying capacity and a deviation indicator to classify townships as attractive or unattractive. The results of this study indicate that: (1) within attractive townships, the greater the deviation from physician carrying capacity, the faster the growth rate of the physician-population ratio; (2) the overall pattern of the growth rate is quite similar across different sizes of townships; and (3) due to a loss of population, unattractive townships do not necessarily have the lowest growth rates of the physician-population ratio even though they gain few physicians. This study thus concludes that market forces are powerful in determining the physician distribution.
\end{abstract}

Key words - physician manpower market, carrying capacity, location pattern, growth rate of physician supply

\section{INTRODUCTION}

Does the geographic distribution of physicians reflect market failure? During the early 1980s Newhouse and his associates applied standard location theory to the pattern of physician practice in the United States and found that:

(1) For any given number of physicians, as town size increases, the likelihood that a town has one or more physicians increases;

(2) Growth rates of physician supply are greater in town sizes at and just below the critical town size; and

(3) The critical town size is smaller for larger specialties (e.g. general and family practitioners) and physicians in such specialties are therefore more diffuse [1-5].

They concluded that market forces play a dominant role in determining the geographic distribution of physicians. Later, Dionne, Langlois and Lemire also showed that the geographic allocation of physicians in the Province of Quebec is consistent with standard location theory [6].

In response, some observers argued that an overall increase in physician supply will not activate market forces to correct imbalances in the geographic distribution of physicians over time. For example, Kindig and Movassaghi reported that despite an overall growth in supply, between 1975 and 1985 the number of physicians per 100,000 residents grew almost three times faster for the entire United States than for small rural counties [7]. Frenzen found that the supply of primary care physicians as well as specialist physicians increased most rapidly in urban areas, thus widening urban-rural differences in the availability of physicians in the United States [8].

In this article, using data from Taiwan, I argue that this controversy resulted from failing to take into account the degree to which the observed physician supply deviates from the physician carrying capacity of a community. Carrying capacity, originally an ecological term, was first applied by Rundall and McClain to explain the great variation observed in the geographic distribution and speciality mix of physicians [9]. They define carrying capacity as the size of the physician population that a community could eventually support, given that the environment has been stable for a long period of time. Because the resources available for physicians are finite and fixed, the carrying capacity of a community for physicians is assumed to be limited. Therefore, it is not the size of a community but the degree of deviation from the carrying capacity of the community that determines the growth rate of physician supply. The greater the deviation from carrying capacity, the faster should be the growth rate of physician supply [10].

\section{THE SITUATION OF TAIWAN}

Taiwan, with a population of 20.8 million in 1992 , is a newly industrialized country. The 1992 GNP per 
capita was US $\$ 10,215$. Life expectancy was 71.9 years for males and 77.2 years for females in 1992 . In that year $6.8 \%$ of the population was aged 65 and over.

Though the impact of Chinese medicine remains rather pervasive, the health care system in Taiwan is structurally dominated by Western medicine [11]. Health care is provided by a mix of public and private sectors [12]. In 1992, there were 11 physicians (not including Chinese medicine doctors) and 48 hospital beds per 10,000 people [13]. More than $80 \%$ of physicians are in private practice; about two-thirds of hospital beds are owned by the private sector. Health care is primarily paid on the basis of fee for service.

In 1991, total health expenditure was $4.8 \%$ of the GNP (US $\$ 421$ per capita), with the public sector accounting for about half of the amount spent [14]. In recent years, government's role has grown through the expansion of social insurance schemes for health care, which are expected to cover the entire population by the end of 1994 .

Regarding health manpower planning, the first health manpower study in Taiwan was carried out by Baker and Perlman in the early 1960s [15]. The physician manpower policy in Taiwan, however, had focused on the production of physicians. Accordingly, the number of physicians increased rapidly from 5937 in 1970 to 11,748 in 1980 , and to 22,365 in 1992 [13].

The geographic distribution of physicians in Taiwan was almost entirely left up to market forces until the group practice centers program was inaugurated in 1983. Under the group practice centers program, the government began to assign physicians who had received medical scholarships to serve in rural areas. By 1992,164 or $44.7 \%$ of all townships in Taiwan had a public group practice center. Because the operation of market forces in Taiwan prior to 1983 was not complicated by government intervention, it provides a good opportunity for investigating the impact of market forces on the geographic distribution of physicians. This study will therefore examine the location pattern of physicians in Taiwan between 1974 and 1982

\section{METHODS}

\section{Measuring deviation from carrying capacity}

One primary task of this study was measuring the deviation from carrying capacity for physicians. Carrying capacity, as mentioned before, is a concept which requires the assumption that the environment has been stable for a long period of time. However, in this study the environment was steadily changing, so carrying capacity was not directly observable. This study thus had to develop a proxy for physician carrying capacity and an indicator of deviation from the carrying capacity. The process started with the following regression model of physician supply:

$$
\mathrm{MD}=\alpha+\beta 1 * \mathrm{POP}+\beta 2 * \mathrm{DENSITY}+\epsilon,
$$

where $\mathrm{MD}=$ the number of physicians practicing in the community, $P O P=$ population size, and DENSITY = population density.

Although many different structural variables have been used as predictors of the number of physicians [16], only population size and population density were addressed in the above model. These two variables were intended to reflect the strength of the demand for health care as well as the quality of living conditions. Other variables which may be conceptually sound were excluded from the model because either their data (e.g. per capita income) were not available or their presence (e.g. proportion of agricultural labor) could cause the serious problem of multicolinearity.

This study then applied the method of ordinary least square (OLS) to estimate the parameters of the model and obtained a predicted value of MD for a given POP and DENSITY. In this study, the predicted value of MD was viewed as a proxy for physician carrying capacity, and the ratio of the predicted value of MD to the observed number of physicians practicing in the community was referred to as the 'deviation indicator' (DI).

\section{Unit of analysis}

The township was selected as the geographic unit of analysis for this study. All of the townships of Taiwan were included in the analysis with the exception of townships in Tainan city, Ilan county, Miaoli county, Nantou county, Kaohsiung county and Penghu county. Data on the number of physicians were not available for the excluded townships. As a result, 276 or $75.2 \%$ of all townships were analyzed.

Five types of townships were identified by using the deviation indicator. First, all townships were divided into 'attractive' (DI $>0$ ) and 'unattractive' $(\mathrm{DI} \leqslant 0)$ townships. Then attractive townships were subdivided into low-deviation (DI $<1$ ), medium-deviation $(1 \leqslant \mathrm{DI}<2)$, and high-deviation $(\mathrm{DI} \geqslant 2)$ townships.

Moreover, townships with population $<30,000$ were referred to as small townships; townships with 30,000 or more people were referred to as large townships.

Table 1. Ordinary multiple regression analysis of the number of physicians on population size and population density (standard errors in parentheses)

\begin{tabular}{lrrr}
\hline Variables & 1974 & 1978 & \multicolumn{1}{c}{1982} \\
\hline Population size & $5.239^{*}$ & $7.616^{*}$ & $7.853^{*}$ \\
$(10,000)$ & $(0.456)$ & $(0.500)$ & $(0.499)$ \\
Population density & $0.186^{*}$ & $0.253^{*}$ & $0.265^{*}$ \\
$\left(100\right.$ persons $\left./ \mathrm{km}^{2}\right)$ & $(0.025)$ & $(0.035)$ & $(0.041)$ \\
& & & \\
Constant & -7.707 & -13.948 & -13.790 \\
$R^{2}$ & 0.519 & 0.624 & 0.635 \\
$F$ & 147.505 & 226.384 & 237.417 \\
\hline$P<0.001$ & & &
\end{tabular}




\section{Sources of data}

This study collected data for three index years: 1974, 1978 and 1982. Data on the number of physicians were obtained from annual statistical abstracts published by city/county governments. Data on population size, population density, and proportion of agricultural labor were obtained from the Taiwan-Fukien Demographic Fact Book published by the Ministry of the Interior, Republic of China.

\section{RESULTS}

Consistent with the findings of previous studies, population size and population density were found to be strongly associated with the number of physicians practicing in a community as shown in Table 1 . Townships with a larger population size or with a higher population density tended to have more physicians. Specifically, the estimated coefficients in Table 1 imply an increase of 5.24-7.85 physicians for every increase in population size of 10,000 people and an increase of $0.19-0.26$ physicians for every increase in population density of 100 persons per square kilometer. The constants are all negative, suggesting that a certain minimum population size and population density are required for a township to have at least one physician. Moreover, the proportion of total variation explained by the model increased from $51.9 \%$ for 1974 to $62.4 \%$ for 1978 , and to $63.5 \%$ for 1982.

Figure 1 displays the geographic distribution of attractiveness to physicians in Taiwan as measured by the deviation indicator. Among 276 study townships, $237(85.9 \%)$ and $218(79.0 \%)$ were attractive townships in 1974 and 1978, respectively. Most of the attractive townships were located at the coastal plains of Western Taiwan, whereas most of the unattractive townships were located at the Central Range which forms a ridge of high mountains and occupies almost half of Taiwan. Thus, when compared with unattractive townships, attractive townships on average had extremely large population sizes, high population densities and low proportions of agricultural labor as shown in Table 2.

Table 2 further indicates that high-deviation townships tended to have smaller population sizes, lower population densities and higher proportions of agricultural labor than low-deviation and medium-deviation townships. However, no significant differences in population size in 1974 and in population density in 1974 and 1978 were found between different types of attractive townships.

Table 3 presents ratios of physicians per 100,000 population by type of township in Taiwan. The overall ratio increased rapidly from 48.6 in 1974 to 64.6 in 1978 , and to 69.3 in 1982 . However, the ratios of attractive townships were substantially higher than those of unattractive townships across all index years. Within attractive townships, low-deviation townships always had the highest ratios. High-deviation townships had lower ratios than medium-deviation townships, but had higher ratios than unattractive townships.

Like the overall ratio, the ratios of both attractive and unattractive townships grew more rapidly over the period 1974-1978 than over the period 1978-1982 (Table 3). However, the overall growth rate of attractive townships was higher than that of unattractive townships between 1974 and 1978, but lower between 1978 and 1982 . Within attractive townships, high-deviation and low-deviation townships always had the highest and lowest growth rates, respectively. As a result, the gap in the availability of physicians between high-deviation and low-deviation townships was reduced over time.

Table 4 presents growth rates of physicianpopulation ratios by type and size of township. Within attractive townships, small and large townships had very similar growth rate patterns across different types of townships. That is, the growth rates of the ratio tended to increase with the degree of deviation from the carrying capacity of the township regardless of size. However, differences in the growth rate between high-deviation and low-deviation townships were greater within small townships than within large townships.

All of the unattractive townships were small townships. Within small townships, unattractive townships had the lowest growth rates over the period 1974-1978, but had higher growth rates than low-deviation and medium-deviation townships over the period 1978-1982 (Table 4).

\section{DISCUSSION}

This study reveals that, within attractive townships, the growth rate of physician supply depends on the degree of deviation from the physician carrying capacity of a township (Table 3), and that the overall pattern of such a dependence is quite similar across different sizes of township (Table 4). Therefore, the Taiwan case examined here supports the contention that market forces are powerful in determining physician distribution.

This study further indicates that the lowest growth rates of the physician-population ratio do not necessarily occur in unattractive townships (Table 4). Such a result can be attributed to the effect of a decrease in population within unattractive townships. Unattractive townships experienced a loss of population during the study periods, while attractive townships gained population rapidly (Table 5). As a result, unattractive townships had a favorable overall growth rate of the physician-population ratio even though they gained few physicians.

The bearing of physician growth rate on the deviation from carrying capacity has profound implications for physician manpower policy. It suggests that the increasing supply of physicians can create 


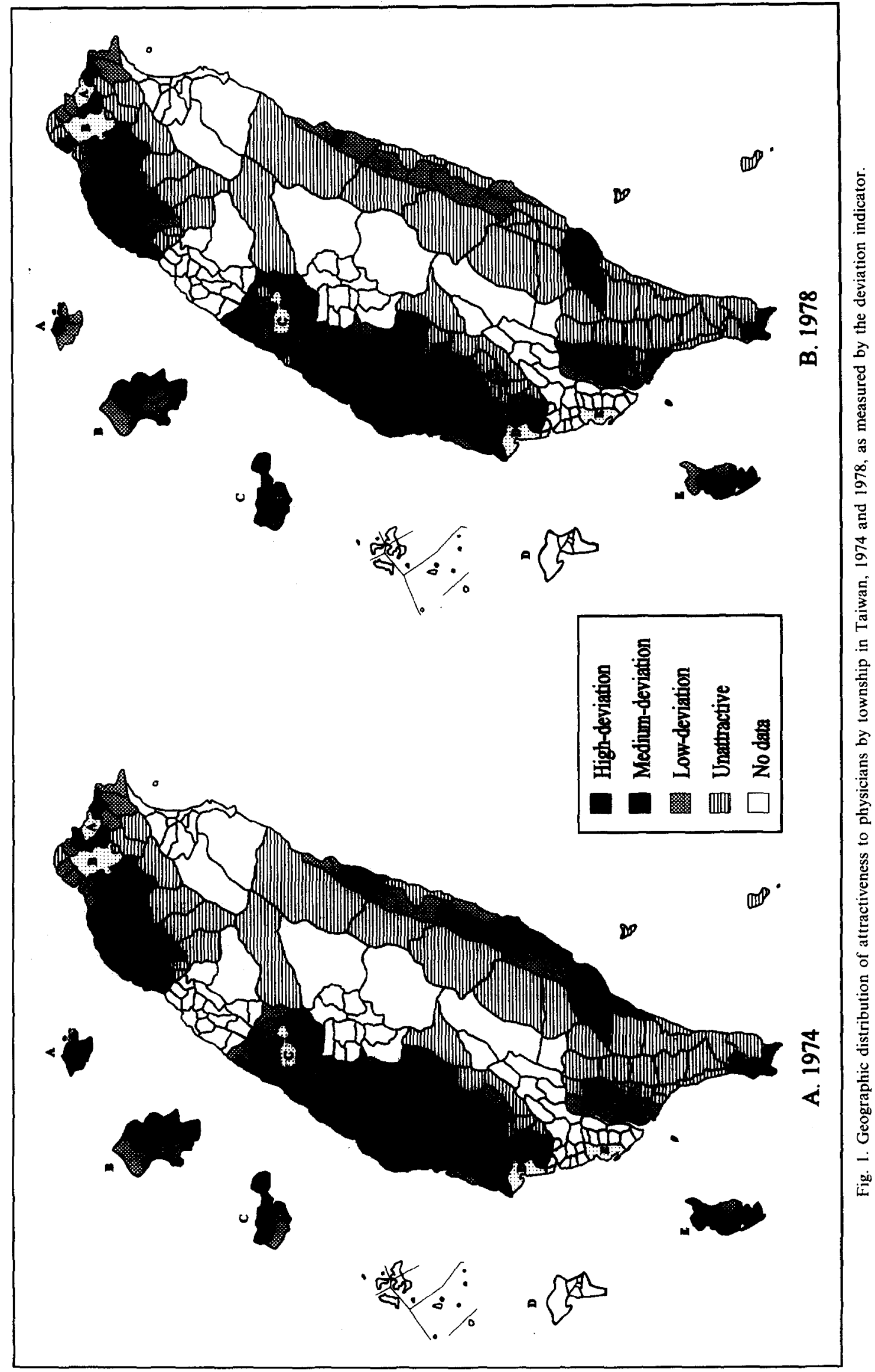


Table 2. Population size, population density and proportion of agricultural labor in Taiwan, 1974 and 1978, by type of township

\begin{tabular}{|c|c|c|c|c|}
\hline Type of township & $\begin{array}{l}\text { Number of } \\
\text { townships }\end{array}$ & $\begin{array}{c}\text { Population } \\
\text { size } \\
(1000)\end{array}$ & $\begin{array}{c}\text { Population } \\
\text { density } \\
\left(100 / \mathbf{k m}^{2}\right)\end{array}$ & $\begin{array}{l}\text { Proportion of } \\
\text { agricultural } \\
\text { labor }(\%)\end{array}$ \\
\hline \multicolumn{5}{|l|}{ (A) 1974} \\
\hline Total & $276^{*}$ & $46.0 \pm 46.5 \ddagger$ & $32.0 \pm 85.1 \ddagger$ & $49.6 \pm 26.4 t$ \\
\hline Attractice townships & 237 & $52.3 \pm 47.3$ & $37.1 \pm 90.8$ & $45.5 \pm 25.7 \S$ \\
\hline Low deviation & 73 & $56.5 \pm 57.9$ & $43.2 \pm 100.4$ & $39.7 \pm 22.8$ \\
\hline Medium deviation & 100 & $54.8 \pm 48.8$ & $38.2 \pm 95.2$ & $42.0 \pm 25.8$ \\
\hline High deviation & 64 & $43.7 \pm 26.4$ & $28.6 \pm 70.6$ & $57.7 \pm 24.9$ \\
\hline Unattractice townships & 39 & $7.7 \pm 3.2$ & $1.1 \pm 1.5$ & $74.5 \pm 14.7$ \\
\hline \multicolumn{5}{|l|}{ (B) 1978} \\
\hline Total & $276+$ & $50.0 \pm 54.8+$ & $32.3 \pm 79.1 \ddagger$ & $45.6 \pm 25.3 \ddagger$ \\
\hline Attractive townships & 218 & $60.7 \pm 57.1 \S$ & $40.5 \pm 87.2$ & $40.7 \pm 24.98$ \\
\hline Low deviation & 61 & $65.9 \pm 73.3$ & $50.7 \pm 100.0$ & $34.2 \pm 24.2$ \\
\hline Medium deviation & 92 & $68.2 \pm 59.5$ & $36.3 \pm 75.3$ & $37.2 \pm 23.2$ \\
\hline High deviation & 65 & $45.2 \pm 24.8$ & $36.7 \pm 91.0$ & $51.9 \pm 24.7$ \\
\hline Unattractive townships & 58 & $10.0 \pm 4.4$ & $1.7 \pm 2.1$ & $64.0 \pm 16.8$ \\
\hline
\end{tabular}

"Grouped according to the degree of deviation from carrying capacity in 1974.

+Grouped according to the degree of deviation from carrying capacity in 1978.

$¥$ Significant differences were found between attractive and unattractive townships according to Wilcoxon rank-sum test $(P<0.001$ for all three variables in 1974 and 1978).

$\S$ Significant differences were found between the three types of attractive townships according to Kruskal-Wallis test $(P<0.01$ for population size in 1978; $P<0.001$ for proportion of agricultural labor in 1974 and 1978).

great incentives for physicians to move into highdeviation townships. However, in order to facilitate the diffusion of physicians, it is important to identify high-deviation townships and make sure that physicians have easy access to information concerning high-deviation townships.

Unattractive townships are short of physicians because their carrying capacity is not sufficient to support many physicians. That is, the shortage of physicians reflects insufficient market rather than market failure in unattractive townships. Therefore, any public policy aimed to induce physicians to practice in unattractive townships should take into account how to raise the carrying capacity of unattractive townships. Some useful strategies may be directly subsidizing physicians or increasing demand for health care through expanding health insurance coverage.
In attempting to generalize from this study, one should note that the analysis was limited to $75.2 \%$ of all townships in Taiwan. Townships which were not included in the analysis tended to have smaller population sizes, lower population densities and higher proportions of agricultural labor than the study townships. However, only the differences in population density were statistically significant $(P<0.05$, Wilcoxon rank-sum test). Since no significant association of population density with the type of attractive township was found (Table 2), the differences in population density seemed unlikely to have biased the conclusion.

This study developed a proxy for physician carrying capacity that became the numerator of the deviation indicator. Because the deviation from the carrying capacity is not directly observable, the use of such a proxy variable is unavoidable. The results of

Table 3. The number of physicians per 100,000 population by type of township in Taiwan over the period 1974-1978 and 1978-1982

\begin{tabular}{|c|c|c|c|c|c|c|c|c|}
\hline \multirow[b]{3}{*}{ Type of township } & \multicolumn{4}{|c|}{$1974-1978$} & \multicolumn{4}{|c|}{$1978-1982$} \\
\hline & \multirow[b]{2}{*}{$\begin{array}{l}\text { Number of } \\
\text { townships* }\end{array}$} & \multicolumn{3}{|c|}{$\begin{array}{l}\text { Number of physicians } \\
\text { per } 100,000 \text { population }\end{array}$} & \multirow[b]{2}{*}{$\begin{array}{l}\text { Number of } \\
\text { townships } \dagger\end{array}$} & \multicolumn{3}{|c|}{$\begin{array}{l}\text { Number of physicians } \\
\text { per } 100,000 \text { population }\end{array}$} \\
\hline & & 1974 & 1978 & $\begin{array}{l}\text { Percent } \\
\text { change }\end{array}$ & & 1978 & 1982 & $\begin{array}{l}\text { Percent } \\
\text { change }\end{array}$ \\
\hline Total & 276 & 48.6 & 64.6 & 32.9 & 276 & 64.6 & 69.3 & 17.7 \\
\hline Attractive townships & 237 & 49.4 & 65.6 & 32.8 & 218 & 66.6 & 71.2 & 6.9 \\
\hline Low deviation & 73 & 87.9 & 109.9 & 25.0 & 61 & 123.0 & 124.2 & 1.0 \\
\hline Medium deviation & 100 & 37.0 & 52.1 & 40.8 & 92 & 49.7 & 55.0 & 10.7 \\
\hline High deviation & 64 & 17.1 & 28.3 & 65.6 & 65 & 25.6 & 33.9 & 32.4 \\
\hline Unattractive townships & 39 & 15.1 & 16.6 & 9.9 & 58 & 18.8 & 21.0 & 11.7 \\
\hline
\end{tabular}

* Grouped according to the degree of deviation from carrying capacity in 1974

tGrouped according to the degree of deviation from carrying capacity in 1978 . 
Table 4. The growth rates of the number of physicians per 100,000 population by type and size of township in Taiwan over the period 1974-1978 and 1978-1982

\begin{tabular}{|c|c|c|c|c|c|c|c|c|}
\hline \multirow[b]{3}{*}{ Type of township } & \multicolumn{4}{|c|}{$\begin{array}{c}\text { Townships with less than } \\
30,000 \text { population }\end{array}$} & \multicolumn{4}{|c|}{$\begin{array}{l}\text { Townships with } \\
30,000 \text { population or more }\end{array}$} \\
\hline & \multicolumn{2}{|c|}{$1974-1978$} & \multicolumn{2}{|c|}{$1978-1982$} & \multicolumn{2}{|c|}{$1974-1978$} & \multicolumn{2}{|c|}{$1978-1982$} \\
\hline & $n^{*}$ & $\%$ & $n \dagger$ & $\%$ & $n^{*}$ & $\%$ & $n \dagger$ & $\%$ \\
\hline Total & 116 & 19.2 & 112 & 3.9 & 160 & 32.7 & 164 & 6.3 \\
\hline Attractive townships & 77 & 19.8 & 54 & 1.2 & 160 & 32.7 & 164 & 6.3 \\
\hline Low deviation & 34 & 10.3 & 27 & -3.6 & 39 & 25.1 & 34 & 0.3 \\
\hline Medium deviation & 23 & 21.8 & 16 & 1.0 & 77 & 40.9 & 76 & 10.4 \\
\hline High deviation & 20 & 64.0 & 11 & 44.6 & 44 & 65.1 & 54 & 31.6 \\
\hline Unattractive townships & 39 & 9.9 & 58 & 11.7 & na & na & na & na \\
\hline
\end{tabular}

*Grouped according to the degree of deviation from carrying capacity in 1974.

tGrouped according to the degree of deviation from carrying capacity in 1978.

Table 5. Mean changes in the number of physicians per township and percent changes in population size and the number of physicians by type of township in Taiwan over the period 1974-1978 and 1974-1982

\begin{tabular}{|c|c|c|c|c|c|c|}
\hline \multirow[b]{3}{*}{ Type of township } & \multicolumn{3}{|c|}{$1974-1978$} & \multicolumn{3}{|c|}{$1978-1982$} \\
\hline & \multirow{2}{*}{$\begin{array}{c}\text { Mean change } \\
\text { in number of } \\
\text { physicians } \\
\text { per township }\end{array}$} & \multicolumn{2}{|c|}{ Percent change } & \multirow{2}{*}{$\begin{array}{l}\text { Mean change } \\
\text { in number of } \\
\text { physicians } \\
\text { per township }\end{array}$} & \multicolumn{2}{|c|}{ Percent change } \\
\hline & & $\begin{array}{l}\text { Number of } \\
\text { physicians }\end{array}$ & $\begin{array}{l}\text { Population } \\
\text { size }\end{array}$ & & $\begin{array}{l}\text { Number of } \\
\text { physicians }\end{array}$ & $\begin{array}{c}\text { Population } \\
\text { size }\end{array}$ \\
\hline Total & 10.0 & 44.5 & 8.7 & 5.2 & 16.1 & 8.3 \\
\hline Attractive townships & 11.6 & 44.8 & 9.0 & 6.6 & 16.2 & 8.8 \\
\hline Low deviation & 16.0 & 32.5 & 5.9 & 6.4 & 8.0 & 6.9 \\
\hline Medium deviation & 12.2 & 60.1 & 13.5 & 8.2 & 24.1 & 12.1 \\
\hline High deviation & 5.5 & 73.3 & 4.6 & 4.4 & 38.2 & 4.4 \\
\hline Unattractive townships & 0.1 & 8.9 & -1.5 & 0.2 & 8.3 & -2.9 \\
\hline
\end{tabular}

township classification on the basis of the deviation indicator seemed satisfactory in this study. However, findings based on a reasonably accurate proxy will be more reliable than those based on a cruder one. Therefore, future research should be directed toward refining the measurement of deviation from the carrying capacity. For example, variables which measure utilization of health services might be used in the regression model of physician supply to improve the validity of the proxy for physician carrying capacity, since such variables measure effective demands for health care more directly.

Finally, Newhouse and his associates argued that "it is not the overall growth of physician supply but rather the growth of physicians in each individual specialty that determines the pattern of geographic distribution" [2]. This study only examined the overall growth rate of physician supply because data on individual specialties were not available. However, by applying the theory of carrying capacity, this study did reach the same conclusion, namely, that market forces determine physician distribution. It is recommended that studies be done to determine whether the deviation from the carrying capacity has the same or different effects among different categories of physicians.

Acknowledgement - This study was supported by a grant from the National Science Council of the Republic of China (NSC77-0301-H002-09).

\section{REFERENCES}

1. Schwartz W. B., Newhouse J. P., Bennett B. W. and Williams A. P. The changing geographic distribution of board-certified physicians. N. Engl. J. Med. 303, 1032, 1980.

2. Newhouse J. P., Williams A. P., Bennett B. W. and Schwartz W. B. Where have all the doctors gone? JAMA 247, 2392, 1982.

3. Newhouse J. P., Williams A. P., Bennett B. W. and Schwartz W. B. Does the geographic distribution of physicians reflect market failure? Bell J. Econ. 13, 493, 1982.

4. Williams A. P., Schwartz W. B., Newhouse J. P. and Bennett B. W. How many miles to the doctor? N. Engl. J. Med. 309, 958, 1983.

5. Newhouse J. P. Geographic access to physician services A. Rev. Public Health 11, 207, 1990.

6. Dionne G., Langlois A. and Lemire N. More on the geographical distribution of physicians. J. Health Econ. 6, 365, 1987.

7. Kindig D. A. and Movassaghi $\mathbf{H}$. The adequacy of physician supply in small rural communities. Health Aff. 8, 63, 1989.

8. Frenzen P. D. The increasing supply of physicians in US urban and rural areas, 1975 to 1988. Am. J. Public Health 81, 1141, 1991.

9. Rundall T. G. and McClain J. O. Environmental selection and physician supply. Am. J. Sociol. 87, 1090, 1982.

10. Hannan M. and Freeman J. The population ecology of organization. Am. J. Sociol. 82, 929, 1977.

11. Lee R. P. Comparative studies of health care systems. Soc. Sci. Med. 16, 629, 1982.

12. Roemer M. I. National Health Systems of the World, Vol. I: The Countries, p. 606. Oxford University Press, New York, 1991. 
13. ROC Department of Health. Health Statistics, Vol. I. ROC Department of Health, Taipei, 1993.

14. Lin S. S. Health expenditure in Taiwan: its financing and allocation (in Chinese). Report to ROC Department of Health, 1993.

15. Baker T. D. and Perlman M. Health Manpower in
A Developing Economy: Taiwan, A Case Study in Planning. The Johns Hopkins University, Baltimore, 1967.

16. Ernst R. L. and Yett D. E. Physician Location and Specialty Choice. Health Administration Press, Ann Arbor, 1985. 